\title{
LA PRODUCCIÓN DE LA CHICHA DE AÑO, COMO RECURSO DE DESARROLLO EN EL DISTRITO DE MAGDALENA DE CAO
}

\author{
THE PRODUCTION OF CHICHA DE AÑO, AS A \\ DEVELOPMENTAL RESOURCE AT MAGDALENA \\ DE CAO DISTRICT
}

\author{
Gianella Pacheco Neyra \\ Ministerio de Cultura, Perú
}

\section{RESUMEN}

Se expone los resultados de la investigación etnográfica realizada en el distrito de Magdalena de Cao, ubicado en el departamento de La Libertad, Perú. La investigación pretende aportar a la comprensión de los cambios que se han generado en la producción, tradición e identidad de los productores de chicha de año. Esta es una bebida alcohólica tradicional que junto al descubrimiento arqueológico de la Señora de Cao, constituye uno de los elementos emblemáticos del distrito. Y es a partir de la llegada de instituciones vinculadas a proyectos de desarrollo y puesta en valor, que los cambios en la tradicional producción de chicha de año se han vuelto más dinámicos. En este proceso se han identificado un grupo de chicheros con disposición a los cambios en el discurso y en las técnicas de producción y un grupo de chicheros renuentes. Se analizan los factores sociales y económicos que influyen en este proceso.

Palabras clave: Tradición, identidad, producción de chicha, chicha de año, Señora de Cao y Magdalena de Cao.

\begin{abstract}
This paper presents the results of an ethnographic research carried out in the district of Magdalena de Cao, located in the department of La Libertad. This work aims to contribute to the understanding of the changes generated in the production, tradition, and identity of the chicha de año makers. Chicha de año is a traditional alcoholic beverage that, along with the Lady of Cao, is one of the most emblematic elements of Magdalena de Cao. Since the arrival of institutions linked to development and enhancement projects, changes in the
\end{abstract}

Este es un artículo Open Access bajo la licencia Creative Commons Atribución-NoComercial-Compartirlgual 4.0

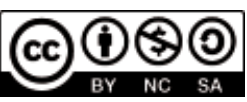


traditional production of chicha de año have become more dynamic. In this process, two groups of chicha makers have been identified, the first one more open to changes in the discourse and production techniques and the second one more reluctant to them. The social an economic factors that influencing this process is analyzed.

Keywords: Tradition, identity, chicha production, chicha de año, Lady of Cao and Magdalena de Cao.

\section{Introducción}

Magdalena de Cao se encuentra en la parte baja del valle de Chicama, sus principales actividades económicas son la pesca artesanal y el cultivo de caña de azúcar. Como otras zonas rurales de la costa norte, viene atravesando un proceso de desarrollo que involucra su patrimonio arqueológico, potencial turístico y el hecho de estar circunscrito a una zona de desarrollo económico creciente. Particularmente este distrito se distingue por contar con dos elementos culturales significativos: la Señora de Cao y la chicha de año.

Desde el año 2006, la presencia de instituciones gubernamentales y no gubernamentales, han aumentado su presencia en el distrito generando cambios e influenciado en la producción, identidad y tradición de los chicheros y chicheras de Magdalena de Cao.

La identidad cultural y la tradición son valoradas de manera distinta en territorios rurales, específicamente en Magdalena de Cao no se conocen cuáles son los valores tradicionales que los productores de chicha otorgan a su actividad y cuáles son los factores que influyen en la disposición por integrar nuevos valores de identidad cultural. Sin embargo, la incorporación de imágenes prehispánicas en las etiquetas de las botellas de chicha, constituye un indicador que es interpretado como apertura al cambio y aprovechamiento de recursos históricos. Asimismo, el embotellamiento y etiquetado de la chicha de año constituye un proceso de «expresión hibrida que está al borde», como refiere García (1992), de lo tradicional y lo moderno, de lo rural y lo urbano. Este proceso conlleva a la pérdida y reinvención de valores, que corren el riesgo de desaparecer o cambiar, sin quedar registradas sus historias, dinámicas y estrategias. Este proceso nos motiva a seguir evaluando los cambios a partir de los nuevos actores en un grupo de la población que desarrolla una actividad tradicional y significativa como es la producción de chicha de año.

\section{Objetivos}

La presente investigación tiene como objetivo general identificar, analizar y explicar cómo las instituciones involucradas en proyectos de desarrollo, ejecutados entre los años 2006 y 2015, han influenciado en la tradición, identidad y producción de los chicheros de Magdalena de Cao. En cuanto a los objetivos específicos, estos son:

- Identificar y caracterizar la influencia que ejercen los discursos y estrategias de los proyectos de desarrollo en la tradición, identidad y producción del grupo de chicheros tradicionales no integrados y en los chicheros modernos, integrados a las instituciones. 
- Identificar los requerimientos necesarios para establecer los lineamientos de una ruta de desarrollo sostenible para la producción de la chicha de año.

Alcanzar estos objetivos nos permitirá esclarecer la manera en cómo se articulan los discursos de identidad sobre una actividad tradicional, en la que existen valores sociales que al parecer no son considerados. Los discursos de identidad son sensibles a la interpretación constante. En ella juegan un rol importante las propias experiencias y situaciones socioeconómicas de los sujetos.

\section{Magdalena de Cao y sus recursos culturales para el desarrollo}

Los estudios en la costa norte peruana sobre desarrollo e identidad cultural se han realizado continuamente a raíz del dinámico incremento de museos y programas de desarrollo en las diferentes instituciones gubernamentales y no gubernamentales (Fonte, 2006; Fonte, Acampora, \& Sacco, 2006; Fonte \& Ranaboldo, 2007; Hernández, 2010; Hernández \& Arista, 2011; Trivelli \& Hernández, 2009). Se identifica algunos cambios generados en la tradición, identidad y producción de los chicheros, a partir de las estrategias y discursos, utilizados por instituciones desde el año 2006 a 2015. Además, se han identificado algunos de los factores que han influido en la adopción y rechazo de estrategias y discursos en el grupo de chicheros. Para la realización de la presente investigación se realizaron 13 entrevistas y un focus group con los chicheros y actores involucrados en la producción y valorización de la chicha de año de Magdalena de Cao.

La chicha de año de Magdalena de Cao es un tipo especial de chicha maíz, de color marrón oscuro y de sabor dulce, que se diferencia de otras chichas del territorio peruano por su largo proceso de fermentación, que generalmente dura alrededor de un año. Esta bebida ha logrado convertirse en un producto tradicional y distintivo del distrito (Ministerio de Comercio Exterior y Turismo, 2015). Si bien la chicha de año se elabora en la mayoría de los hogares de Magdalena de Cao, la chicha de mayor reconocimiento mantiene procesos tradicionales que la caracterizan, y la distinguen, siendo producida solo por algunas personas. Los parámetros, creencias y técnicas de producción de la chicha se transmiten de los familiares mayores a los más jóvenes. Este conocimiento es valorado por la mayor parte de la población, y los chicheros son cuidadosos de no revelar los procedimientos de manera abierta a personas que no se dediquen o estén involucrados en la producción de chicha. Otra característica importante de la producción es la valorización de la tradicionalidad, los chicheros conservan su prestigio en la medida que mantienen los procesos de producción y utilizan materia prima original.

En la última década la producción de chicha de Magdalena de Cao ha atravesado uno los cambios más drásticos, transformándose paulatinamente de ser un producto artesanal y de venta local a ser un producto semiindustrial, para la venta turística, en botellas etiquetadas. Este cambio se debe al aumento de turistas que visitan el complejo arqueológico El Brujo y su moderno museo de sitio, y a los proyectos de desarrollo, que a partir del descubrimiento de la Señora de Cao, entre otros, han aumentado su presencia en el distrito.

La denominada Señora de Cao, son los restos de una mujer, que habría sido una poderosa gobernante Mochica, y que ha atraído el interés de la comunidad científica y de diferentes instituciones, que ven en este descubrimiento un atractivo para el desarrollo turístico, cultural y económico. Este descubrimiento es notable 
ya que pone en evidencia el importante rol de la mujer en la política prehispánica peruana. En el año 2006 se realizó la inauguración del Museo de Cao, en el que se expusieron los restos de la Señora de Cao. Este evento causó gran expectativa y contó con la presencia de autoridades nacionales e internacionales.

A partir de este mismo año se generó un mayor interés en instituciones como la Municipalidad, el Museo de Cao, y la ONG MINKA, quienes desarrollaron diferentes proyectos de desarrollo, influyendo y potencializado las actividades económicas y culturales. Estas instituciones representan un factor influyente en el proceso de puesta en valor del patrimonio cultural de Magdalena de Cao, en donde la «codecisión de la población aún es muy limitada» (Hernández, 2010, p. 2). La situación de Magdalena de Cao se desarrolla dentro de un contexto favorecedor, ya que los productos y técnicas artesanales de esta región son considerados productos generadores de ingresos y herramientas para el desarrollo (Hernández, 2010). En este sentido la chicha de año constituye un elemento con potencial económico y cultural, ya que se produce de manera tradicional para la demanda local y se viene adaptando a un formato semiindustrial para la creciente demanda turística.

Las expectativas de mejoras económicas de la población están asociadas al incremento de turistas extranjeros, sin embargo, muestran desconfianza en las instituciones, y los discursos y estrategias no han logrado ser asimilados de manera integral por la población y los grupos de productores de chicha de año.

Las instituciones estudiadas utilizan las implicancias simbólicas e identitarias de la chicha en sus diferentes discursos e iniciativas:

\section{Acciones realizadas por las instituciones y la influencia en la producción de chicha de año}

La Municipalidad de Magdalena de Cao, siempre ha tenido especial interés en el desarrollo turístico. En 1999 antes que los hallazgos de la Señora de Cao atrajeran la mirada de las ONG y se inaugurará el Museo de Cao, se creó un Museo Municipal, con piezas arqueológicas donadas por la misma población. Luego, en el 2006 se incrementaron los programas de promoción turística, dentro de los planes de desarrollo territorial del municipio. Además, se desarrollaron programas para la formación de orientadores locales, talleres artesanales, asesoramiento para la implementación de restaurantes, venta de chicha de año y artesanías y festivales de productos artesanales. En el 2007 la municipalidad incorporó a su escudo de armas la imagen de la Señora de Cao, como figura central. ${ }^{1}$ La Municipalidad ha realizado diferentes obras públicas con el objetivo de desarrollar mejores condiciones para el turismo, entre estas obras destaca el asfaltado de las carreteras, la implementación la normatividad de conservación y desarrollo urbano del casco central del pueblo, así como la coordinación con la Policía Nacional para brindar la seguridad ciudadana en el tramo turístico de Magdalena de Cao.

Con respecto a la promoción de la chicha de año, la Municipalidad ha realizado diferentes acciones con el objetivo de conseguir fondos para implementar una planta de producción semiindustrial, en este proceso se iniciaron los trámites para la obtención de un registro sanitario, pero debido a la ausencia de recursos económicos,

1 Antes al descubrimiento de la Señora de Cao, tenía un guerrero Mochica. 
el proceso quedó inconcluso. Por otro lado, la Municipalidad ha implementado dentro del calendario festivo una fecha para celebrar la producción local de chicha de año, iniciándose desde el 2015: El I Festival de chicha de año, como parte de las festividades realizadas por el 477 aniversario de fundación española de Magdalena de Cao. Este festival contó con la participación de los productores de chicha más reconocidos del pueblo.

La ONG MINKA es, desde el año 2007, una de las instituciones más activas en el desarrollo turístico de Magdalena de Cao, participó del proyecto Turismo Arqueológico Ruta Mochica, que tuvo por finalidad ayudar a las pequeñas y microempresas (Mypes) realizando talleres para mejorar la calidad de los productos y capacitando en estrategias de mercadeo, a través del uso de iconografía Moche. ${ }^{2}$ La apropiación de iconografía como medio de vincular el turismo arqueológico a negocios locales de tipo turístico, es una táctica utilizada por muchas de estas organizaciones en la región y al parecer es la estrategia que mayor éxito tiene.

Esta ONG también ha realizado capacitaciones para la venta organizada, embotellamiento, etiquetado y mejoramiento de las condiciones de salubridad. Además ha logrado que un grupo de productores se asocien para vender su chicha en tiendas turísticas del distrito, en donde además, se ofrece degustación de la bebida.

El Museo de Cao promueve la preservación del patrimonio arqueológico y difunde a través de medios de comunicación y de discursos, cada vez menos técnicos y más creativos, la importancia del patrimonio arqueológico regional y local. Este último aspecto es importante y útil para la atención mediática, captación de fondos y para el desarrollo turístico. Hernández (2010) da cuenta de cómo estas mismas estrategias son utilizadas en diferentes museos de la Costa Norte por lo que es importante diferenciarse y hacerse de una «marca». ${ }^{3}$ En este sentido, el Museo se distingue por tener los restos de la Señora de Cao, que constituye un elemento significativo para la zona. Específicamente con el grupo de productores de chicha, el Museo de Cao no ha organizado ninguna actividad ni proyecto específico, sin embargo, fomenta el uso de iconografía e imágenes del sitio arqueológico. Estas imágenes, pintadas y en relieve, están presentes frecuentemente en las fachadas e interiores de los negocios turísticos, pero también en las calles y casas particulares (Figura 1). Los chicheros han adoptado estas mismas imágenes para las etiquetas de sus botellas y nombres de sus productos (Figura 2).

En resumen, las instituciones estudiadas han orientado sus acciones hacia la población involucrada con el turismo. Uno de estos grupos, en los que se ha tomado especial interés, son los productores de chicha, ya que son los proveedores del producto más emblemático y tradicional de Magdalena de Cao. La finalidad de estos proyectos de desarrollo, es promover la venta y consumo de chicha de año y ampliar su mercado a los turistas que visitan el complejo arqueológico El Brujo. Para esto utilizan estrategias y discursos en los que se articula la tradición e identidad local con referencias de un pasado prehispánico común. De manera complementaria los programas buscan incrementar el turismo gastronómico e insertar la chicha de año dentro de una red de negocios de venta de artesanías y restaurantes.

\footnotetext{
Proyecto financiado por la Fundación Wiesse y el Banco Interamericano de Desarrollo (BID).

Entre los museos figuran: Museo de Sitio de Túcume, Museo de Sitio Huaca Rajada Sipan, Museo de Sitio de Huacas del Sol y de la Luna.
} 
Figura 1. Vista de negocio turístico con iconografías prehispánicas.

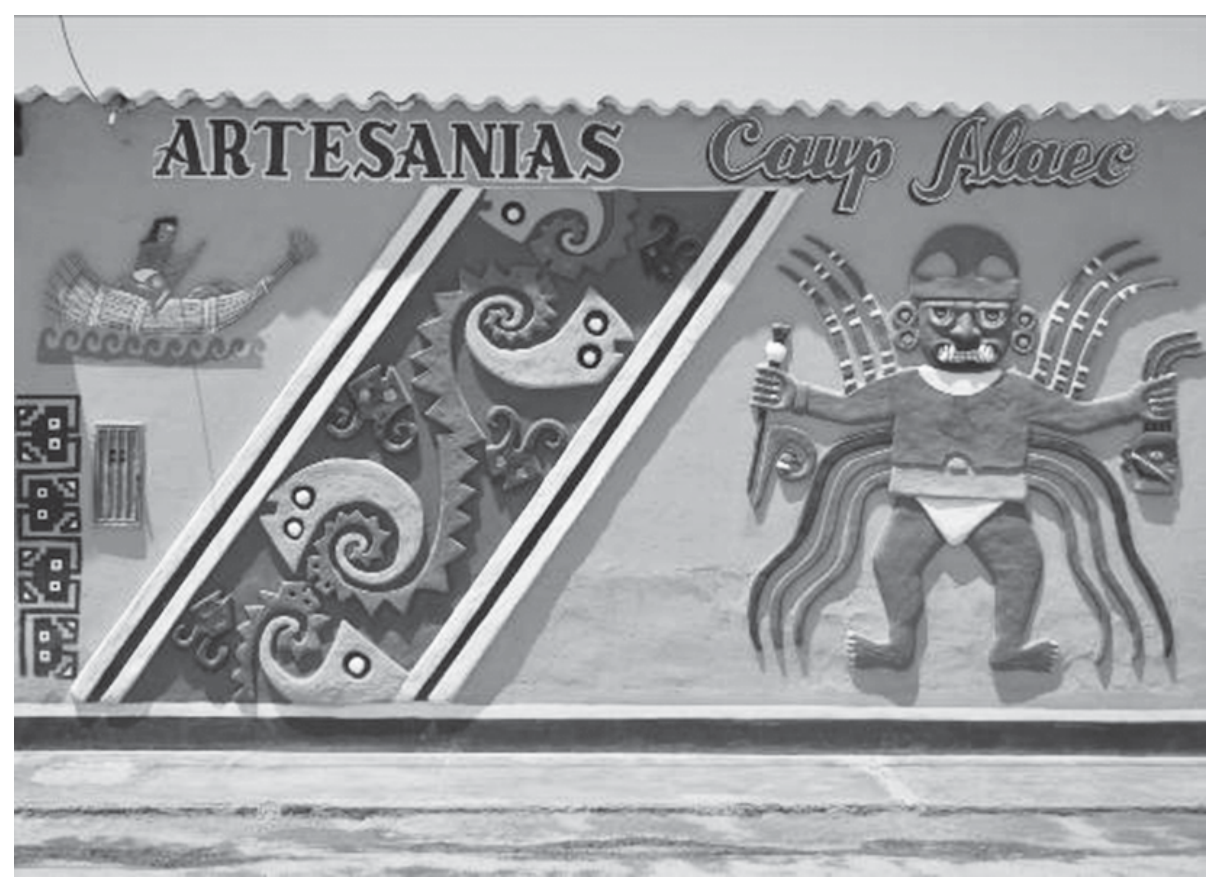

Fuente: Pacheco. Trabajo de campo, 2014

Figura 2. Botellas de chicha con iconografía Moche.

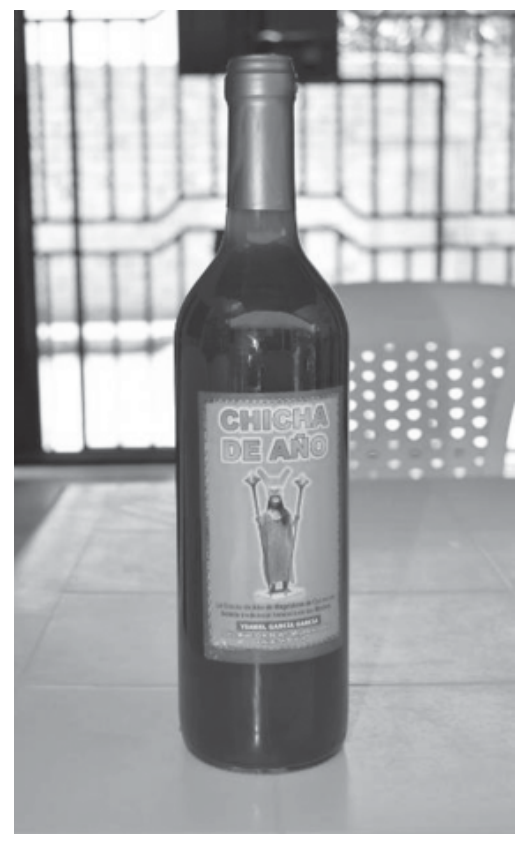

Fuente: Pacheco. Trabajo de campo, 2014 


\section{Resultados}

\section{Programas de desarrollo, influencias y problemas}

El grado de aceptación los discursos y estrategias de las instituciones y programas de desarrollo varía entre los chicheros. Esto se debe a diferentes problemas ligados a la falta de recursos y a las diferentes perspectivas de valoración de la producción, tradición e identidad:

- La falta de sostenibilidad de los proyectos de desarrollo parece ser uno de los principales problemas. Los productores de chicha valoran las capacitaciones realizadas por la ONG, pero sostienen que éstas han durado muy poco tiempo y que luego de terminar los dejan sin ningún tipo de apoyo. Debido a esto los productores actualmente se muestran reacios a participar de reuniones y capacitaciones de otros proyectos de desarrollo. Con respecto a la labor municipal, representan una iniciativa importante para el desarrollo de esta actividad, sin embargo, el poco presupuesto que maneja y la falta de mayor personal técnico calificado, sumado a la desconfianza en las autoridades políticas, no ha permitido tener una aceptación integral de los discursos y estrategias que trata de desarrollar en los productores de chicha.

- La poca valoración que dan los promotores de los proyectos de desarrollo a la importancia social de la producción de chicha. Particularmente, la transmisión y manejo de conocimientos de la producción de chicha, dentro del grupo social, no son del todo conocidos ni valorados por las personas que conducen los proyectos de desarrollo. El embotellamiento semiindustrial de la chicha de año, así como la intención de estandarizar los procesos de producción, afecta los modos de producción y el sistema de transmisión de conocimiento de chicheros mayores hacia los más jóvenes, que es valorado por ser de índole local propio, y de restrictiva difusión. Este aspecto origina el estatus de las chicheras dentro de la localidad ya que para lograr una chicha de año de calidad se debe alcanzar un conocimiento especializado logrado por la experiencia y no solo por la tecnificación.

- Las instituciones consideran a la chicha principalmente como un bien económico cultural, y no tanto un bien social que sirve para generar vínculos con las localidades vecinas, especialmente con Cartavio, centro de comercio con el que se establece relaciones de colaboración, prestigio y vínculos de clientelismo. Muchos chicheros, a través de descuentos, comida extra y regalos de chicha de año logran hacerse de clientes recurrentes, que a su vez refieren a otros amigos, aumentando de esta manera los consumidores de las chicherías y también logran comprometer a sus clientes con favores y/o servicios profesionales.

- Los talleres y programas están dirigidos a un grupo reducido de chicheros, los cuales para adoptar las nuevas estrategias de producción (embotellamiento y etiquetado) y venta deben contar con capacidad de inversión. Esta restricción deja de lado a aquellos productores que por lo general son los más experimentados y de mayor edad. 
La chicha de año, constituye un patrimonio cultural que se visualiza más allá de la transmisión de conocimientos, se recrea en un proceso de innovación que incluye diferentes actores ubicados entre lo local y regional, lo cual implica tener una visión de la dinámica de la tradición y de los discursos de identidad. Bajo esta perspectiva de la revivificación de la tradición se debe considera la importancia de los valores sociales.

\section{Conclusiones}

1. La producción de chicha de año es reconocida en contextos locales y regionales, constituyéndose como una marca propia de Magdalena de Cao, la cual gradualmente se va haciendo conocida a través de la población y de sus consumidores.

2. Segmentos crecientes de la población local y regional reconocen en la chicha de año un elemento que ofrece sentido de pertenencia, vinculando identidad y tradición; proporcionando, además, una oportunidad de ingresos económicos.

3. La influencia de los discursos y estrategias de las instituciones en la producción de la chicha de año solo afecta a una parte de los productores, definidos como los chicheros «modernos», quienes representan un grupo minoritario dentro del grupo total de chicheros. Este grupo de personas están dispuestas a la modernización de la producción de la chicha de año. Se diferencian por ser más jóvenes y con mayor capacidad de inversión.

4. La conectividad y comunicación entre las instituciones y los productores de chicha es uno de los principales problemas que enfrentan los programas de desarrollo. Estas instituciones no logran vincularse a través de sus discursos y estrategias de manera significativa e integral. A pesar de ello, el incremento del turismo crea expectativas de desarrollo económico y cierta disposición a participar de estos programas.

5. La producción de chicha de año es una actividad asociada mayormente a mujeres, agricultores y personas mayores de 60 años. Este grupo es precisamente el que tiene menor acceso a recursos económicos. En este sentido, los valores asociados a esta actividad se vinculan al reconocimiento público de los saberes y capacidades de un grupo minoritario de la población de Magdalena de Cao.

6. Los productos con identidad, como la chicha de año, representan colectividades y estrategias propias, que de manera complementaria pueden incluir estrategias y discursos de instituciones y programas de desarrollo, que potencializan sus propias estrategias.

7. Se aprecia una red emergente de actores dedicados a explorar estrategias de desarrollo basadas en la valorización de los activos culturales en territorios rurales.

8. Existe un creciente interés en mejorar la gestión municipal para ejecutar proyectos de puesta en valor. Se observa el aumento de consumidores regionales y extranjeros, que prefieren productos diferenciados por su origen y asociación cultural. 
9. En Magdalena de Cao la producción de chicha de año ha tenido una dinámica similar con respecto a las chicherías de la costa norte del Perú. Se ha ido reduciendo el número de personas dedicadas a esta actividad, a pesar del incremento turístico, ya que esta actividad no logra satisfacer las demandas económicas de la creciente población.

10. La transmisión de conocimientos de los chicheros con mayor experiencia hacia los chicheros más jóvenes es cada vez menor.

11. Las técnicas tradicionales de la producción de chicha de año son transmitidas de los chicheros adultos a los chicheros más jóvenes, lo que genera prestigio social vinculado a la experiencia. Si la chicha de año se llegara a industrializar, los conocimientos técnicos de la producción tradicional no seguirían siendo restringidos y asociados a la experiencia local. Esta situación conllevaría a la pérdida del valor social de los chicheros mayores.

\section{Referencias}

Fonte, M. (2006). Desarrollo territorial y reflexiones teóricas y casos empíricos. Recuperado de htttp://www.rimisp.org/ getdoc.php?docid=5102

Fonte, M., Acampora, T., \& Sacco, V. (2006). Economía de la cultura y desarrollo rural: reflexiones teóricas y caso empíricos. Proyecto de Desarrollo Territorial a partir de servicios y productos con identidad. Recuperado de www.rismip.org/ TerritorioeIdentidad

Fonte, M., \& Ranaboldo, C. (2007). Desarrollo rural, territorios e identidades culturales. Perspectivas desde América Latina y la Unión Europea. Opera, 7, 9-31.

García, N. (1992). Culturas híbridas: estrategias para entrar y salir de la modernidad. Buenos Aires: Ediciones Sudamericana.

Hernández, R. (2010). Arqueología, museos y desarrollo territorial rural en la costa norte de Perú. Lima: Instituto de Estudios Peruanos - IEP.

Hernández, R., \& Arista, A. (2011). Arqueología, museos y desarrollo en el Perú. Lima: Instituto de Estudios Peruanos - IEP.

Ministerio de Comercio Exterior y Turismo (2015). De mi tierra un Producto: Magdalena de Cao (Folleto informativo). Lima: Mincetur.

Trivelli, C., \& Hernández, R. (2009). Apostando por el desarrollo territorial rural con identidad cultural: La puesta en valor del patrimonio prehispánico de la Costa Norte del Perú. En C. Ranaboldo y A. Schejtman (editores), El valor del patrimonio cultural (pp. 201236). Lima: Instituto de Estudios Peruanos - IEP. 